was analysed by qPCR and ELISA. CD4 ${ }^{+}$T cells were stimulated with anti-CD3/ anti-CD28 beads (ratio 1 bead: 5 cells) alone or in combination with recombinant human Sema4A $(200 \mathrm{ng} / \mathrm{ml})$, in the presence or absence of neutralising antiNRP1 or PlexinD1 antibodies, and the expression of PlexinB2, PlexinD1, NRP-1 and the production of Th17 cytokines was analysed by qPCR, ELISA and flow cytometry.

Results: Plasma levels of Sema4A were significantly higher in SSc patients compared to healthy controls $(\mathrm{HC})$ and positively correlated $(\mathrm{r}=0.611)$ with the skin disease severity. Sema4A and PlexinB2 expression was significantly higher in monocytes and $\mathrm{CD}^{+} \mathrm{T}$ cells from SSc patients, respectively. Moreover, Poly IC and CXCL-4 significantly up-regulated the expression and secretion of Sema4A in monocytes from SSc patients, and $\mathrm{CD}^{+} \mathrm{T}$ cells stimulation with anti-CD3/antiCD28 beads increased the expression of PlexinB2 and NRP-1 in both HC and SSc patients. Finally, functional assays showed that Sema4A significantly enhanced the expression of Th17 cytokines induced by CD3/CD28 in CD4 ${ }^{+} \mathrm{T}$ cells from both $\mathrm{HC}$ and SSc patients, and the blocking of the Sema4A signalling using neutralising antibodies anti-PlexinD1 and anti-NRP-1 significantly reduced this expression. Importantly, the Sema4A-induced IL-17 secretion was significantly higher in stimulated CD4 ${ }^{+} \mathrm{T}$ cells from SSc patient compared to $\mathrm{HC}$.

Conclusions: Sema4A signalling is deregulated in SSc patients and plays an important role in Th17 skewing. Therefore, Sema4A and its receptors could be promising therapeutic targets for the treatment of SSc.

Disclosure of Interest: None declared

DOI: 10.1136/annrheumdis-2018-eular.3692

\section{AB0194 SPARC IS ELEVATED IN THE AFFECTED SKIN OF SYSTEMIC SCLEROSIS PATIENTS AND INDUCES THE EXPRESSION OF FIBROTIC GENES IN DERMAL FIBROBLASTS AND MACROPHAGES}

S. García Pérez ${ }^{1}$, B. Malvar Fernández ${ }^{1}$, M. Bergin ${ }^{2}$, T. Johnson ${ }^{2}$, W. Marut ${ }^{1}, \mathrm{~K}$. A. Reedquist ${ }^{1}$, T.R. Radstake ${ }^{1}$. ${ }^{1}$ Laboratory for Translational Immunology (LTI) and Department of Rheumatology and Clinical Immunology, University Medical Center Utrecht, Utrecht, Netherlands; ${ }^{2}$ UCB, Slough, UK

Background: Systemic sclerosis (SSc) is an autoimmune disease characterised by inflammation, vascular injury and excessive fibrosis in multiple organs. SPARC is a matricellular glycoprotein that can bind to extracellular matrix (ECM) components, as well as cellular receptors and secreted growth factors. In doing so, SPARC regulates biological activities dependent upon cellular interactions with the ECM as well as processes dependent upon cell adhesion, including tissue remodelling, wound healing, angiogenesis and immune responses. Several studies have implicated SPARC in the pathology of SSc but the specific role of SPARC in fibrosis is still unknown.

Objectives: The aim of this study was to analyse the potential role of SPARC as a regulator of fibrosis in SSc.

Methods: Expression of SPARC in the skin of healthy donors (HD) and SSc patients was measured by immunohistochemistry. Peripheral blood-derived monocytes from HD and SSc patients were differentiated into macrophages with M-CSF $(25 \mathrm{ng} / \mathrm{ml})$. Dermal fibroblasts and M-CSF macrophages from both HD and SSc patients were stimulated with SPARC $(0.1$ and $1 \mu \mathrm{g} / \mathrm{ml})$ for 6 hour and 24 hour. mRNA and protein expression of SPARC and other fibrosis-related genes were measured by qPCR and western blot.

Results: We found increased expression of SPARC in the affected skin of SSc patients compared to HD. We also observed a higher expression of SPARC and ECM components (colagen(Col)-1 and fibronectin-1 (FN1) in dermal fibroblasts derived from SSc patients. SPARC stimulation induced mRNA expression of important fibrosis-related genes such as TGFB1, PDGFB, SERPINE1 and CTGF, and ECM components including COL1A1,COL3A1,COL4A1 and FN1 in dermal fibroblasts from SSc patients, but not healthy donors. In M-CSF macrophages from SSc patients, SPARC also up-regulated mRNA expression of TGFB1, $P D G F B, S T A B 1, C O L 1 A 1$ and $F N 1$.

Conclusions: These results suggest that SPARC is an important pro-fibrotic mediator contributing to the pathology driving SSc. Therefore, SPARC could be a promising therapeutic target for reducing fibrosis in SSc.

Disclosure of Interest: S. García Pérez: None declared, B. Malvar Fernández: None declared, M. Bergin Employee of: UCB, T. Johnson Employee of: UCB, W. Marut: None declared, K. A. Reedquist: None declared, T. R. Radstake: None declared

DOI: 10.1136/annrheumdis-2018-eular.3702

\section{$\mathrm{AB} 0195$}

PROTEOMIC APPROACH IDENTIFIES DIFFERENTIAL PROTEIN EXPRESSION IN CULTURED FIBROBLASTS UNDER STIMULATION WITH TGF-B1

S. Vivier ${ }^{1}$, A. Chepy ${ }^{1,2,3}$, F. Bray ${ }^{4}$, T. Guerrier ${ }^{1,5}$, M. Balden $^{1,5}$, C. Rolando ${ }^{4}$, E. Hachulla ${ }^{1,2,3}$, D. Launay ${ }^{1,2,3}$, S. Dubucquoi ${ }^{1,2,5}$, V. Sobanski ${ }^{1,2,3}$. ${ }^{1}$ Lille Inflammation Research International Center (LIRIC), Univ. Lille, U995; ${ }^{2}$ Département de Médecine Interne et Immunologie Clinique; ${ }^{3}$ Centre national de référence maladies systémiques et auto-immunes rares (sclérodermie systémique), CHU Lille; ${ }^{4}$ Miniaturisation pour la Synthèse, l'Analyse and la Protéomique (MSAP), CNRS, USR 3290; ${ }^{5}$ Institut d'Immunologie, Centre de Biologie Pathologie, CHU Lille, F-59000 Lille, France

Background: Fibroblasts (Fb) are key effectors cells in systemic sclerosis (SSc). ${ }^{1} \mathrm{Fb}$ stimulation with TGF- $\beta 1$ is usually considered as the positive control in studies assessing the fibrogenesis in SSc. ${ }^{2}$ Yet, the lack of standardisation of TGF- $\beta 1$ stimulation might be responsible for discrepancies in experiments performed in different conditions. Proteomic approach allows the analysis of differential expression of the whole proteins (proteome) in $\mathrm{Fb}$, and appears an interesting approach to compare different culture conditions.

Objectives: We designed this study to compare the whole protein expression in Fb stimulated by TGF- $\beta 1$ in different conditions.

Methods: At fifth passage, primary culture of human $\mathrm{Fb}$ from healthy subjects (ATCC; PCS-201-012) were stimulated or not with different concentrations of recombinant human active TGF- $\beta 1(0.04,1$, and $5 \mathrm{ng} / \mathrm{mL})(R$ and D Systems; 240-B-002) during 24, 48 and 72 hours. Proteins were extracted and analysed using an eFASP LC-MS/MS approach on an Orbitrap mass spectrometer (Thermo Scientific; Q Exactive +). Proteins quantitation was performed by Maxquant and statistical analysis by Perseus using ANOVA and principal component analysis (PCA).

Results: A total of 3267 proteins were identified, of which 1957 showed differential expression using ANOVA analysis. PCA revealed several clusters of differential proteins expression (figure 1). There were clear clusters of protein expression related to (i) unstimulated and stimulated conditions, (ii) between the three different times of stimulation and (iii) to TGF- $\beta 1$ concentrations used. Although the expression of proteins in $\mathrm{Fb}$ exposed to 0.04 and $1 \mathrm{ng} / \mathrm{mL}$ of TGF- $\beta 1$ during 72 hour were rather close, there was a unique proteins profile related to the condition with $5 \mathrm{ng} / \mathrm{mL}$ of TGF- $\beta 1$ during 72 hour.

Figure 1: PCA representation of differential proteins expression in different conditions. [TGF- $\beta 1]=0.04 \mathrm{ng} / \mathrm{mL}$ : square; [TGF- $\beta 1]=1 \mathrm{ng} / \mathrm{mL}$ : circle; [TGF- $\beta 1]=5 \mathrm{ng} /$ $\mathrm{mL}$ : diamond. The more the points appear distanced, the more different is the protein expression.

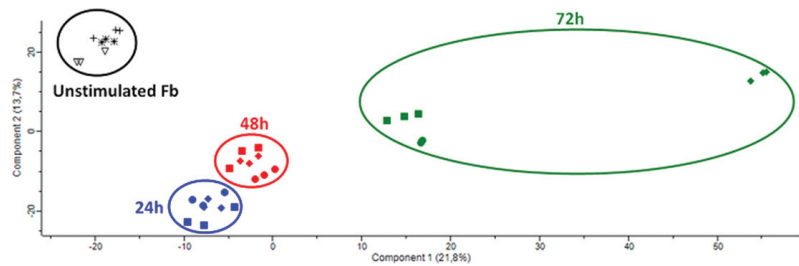

Abstract AB0195 - Figure 1. PCA representation of differential proteins expression in different conditions.

Conclusions: This study highlights a variation of proteins expression depending on both stimulation time and TGF- $\beta 1$ concentrations in Fb culture. The identification of protein differentially expressed will provide insights in the impact of TGF- $\beta 1$ on $\mathrm{Fb}$ physiology under stimulation conditions. These data underline the need of standardisation of culture conditions to allow inter-data comparisons using in sensitive "omic" approaches.

REFERENCES:

[1] Garret SM, Frost DB, Feghali-Bostwick C. The mighty fibroblast and its utility in scleroderma research. J Scleroderma Relat Disord 2017;2(2):69-134

[2] Verrecchia F, Mauviel A. Transforming growth factor-beta signaling through the Smad pathway: role in extracellular matrix gene expression and regulation. J Invest Dermatol 2002 Feb;118(2):211-5.

Disclosure of Interest: None declared DOI: 10.1136/annrheumdis-2018-eular.6633 